\title{
Autoimmune urticaria
}

\author{
ANNA SADOWSKA-PRZYTOCKA ${ }^{\prime}$, MAGDALENA CZARNECKA-OPERACZI', KATARZYNA ŁĄCKA ${ }^{2}$, \\ DOROTA JENEROWICZ
}

${ }^{1}$ Department of Dermatology, Poznan University of Medical Sciences, Poland

${ }^{2}$ Department of Endocrinology, Metabolism and Internal Medicine Poznan, University of Medical Sciences, Poland

\begin{abstract}
Chronic urticaria is a common skin disorder characterized by spontaneously appearing wheals and flare-type skin reactions, with or without angioedema. Skin lesions usually persist up to 24 hours and patients generally report pruritus and/or burning sensation. According to the current EAACI/GA2LEN/EDF/WAO guidelines, urticaria may be classified as spontaneous, physical and other types of the disease. Spontaneous urticaria in relation to the duration of the process is further divided into acute and chronic spontaneous types. In contrast to physical and other variants of urticaria, in the spontaneous type, lesions usually occur without any obvious stimuli. It has been demonstrated that in about one-third of patients with chronic spontaneous urticaria, positive response to their own serum is being recorded in the autologous serum skin test (ASST). In general, a positive result of ASST reflects autoreactivity and may be regarded to be the basis for further investigations in order to characterize the causative factors. Interestingly, patients suffering from chronic spontaneous urticaria with a positive result of ASST present with longer duration and more severe course of the disease and higher requirements for antihistamines and/or alternative methods of treatment.
\end{abstract}

Key words: autoimmune urticaria, autoreactivity, antihistamines, treatment.

(Centr Eur J Immunol 2013; 38 (2): 265-270)

\section{Introduction}

According to the contemporary definition proposed by EAACI/GA2LEN/EDF/WAO, urticaria is a highly heterogeneous group of diseases with a common clinical manifestation of an urticarial wheal (flare-type skin reaction) with or without angioedema [1]. Urticarial wheals are flat, edematous and palpable patches; porcelain or white to pale red in color; of various size and shape. They appear rapidly and usually persist up to 24 hours, without any secondary type of lesions left behind. Skin eruptions are often accompanied by pruritus and/or burning sensation of the skin [2]. There is no predilection being observed in urticaria, therefore any skin region may be involved in the process.

From the histological standpoint, a classical urticarial wheal is characterized by the swelling of the upper layers of the dermis and the widening of blood postcapillary and lymphatic vessels. If the process is located in the deeper layers of the dermis and/or involves the subcutaneous tissue, angioedema (Quincke's edema) is diagnosed. Angioedematous swelling usually involves the face (eyelids, lips) and genital areas. A combination of urticarial wheals and angioedema is being detected in approximately $50 \%$ of all cases, while in $40 \%$ and $10 \%$ - isolated wheals or angioedema, respectively, are being observed [3]. The disease may occur regardless of the age with a significant predominance of the female gender $(\mathrm{M}: \mathrm{F}-4: 1)$ [4]. Several different classifications of urticaria which relate to various spectra of causative factors have been proposed. But first of all duration of the disease seems to be of the main importance. 6 weeks' duration of recurrent urticarial flares has been established to be a borderline between the acute and chronic variants of the disease. Importantly, $20-30 \%$ of patients with acute urticaria will suffer further on, from the chronic form of disease. From the etiological standpoint, acute urticaria is mainly associated with allergy to drugs and/or alimentary allergens as well as to acute infections (viral and bacterial in origin). On the other hand, in the case of chronic urticaria, a complex, multifactorial etiological background should be suspected and investigated. Table 1 presents one of the contemporary classifications of urticaria and Fig. 1 summarizes the proposal of the general diagnostic approach [1].

Correspondence: Anna Sadowska-Przytocka, Department of Dermatology, Poznan University of Medical Sciences, Przybyszewskiego 49, 60-355 Poznań, Poland, e-mail: a.sadowska80@gmail.com 
Table 1. Classification of urticaria [1]

\begin{tabular}{lll}
\hline Types & Subtypes & Definition \\
\hline spontaneous urticaria & $\begin{array}{l}\text { acute spontaneous urticaria } \\
\text { chronic spontaneous urticaria }\end{array}$ & $\begin{array}{l}\text { spontaneous wheals and/or angioedema }<6 \text { weeks } \\
\text { spontaneous wheals and/or angioedema }>6 \text { weeks }\end{array}$ \\
\hline physical urticaria & $\begin{array}{l}\text { cold contact urticaria } \\
\text { delayed pressure urticaria } \\
\text { heat contact urticaria } \\
\text { solar urticaria } \\
\text { urticaria factitia/demographic urticaria } \\
\text { vibratory urticaria/angioedema }\end{array}$ & $\begin{array}{l}\text { eliciting factor: cold objects/air/fluids/wind } \\
\text { eliciting factor: vertical pressure } \\
\text { eliciting factor: localized heat } \\
\text { eliciting factor: UV and/or visible light } \\
\text { eliciting factor: mechanical shearing forces (wheals }- \\
\text { arising after 1-5 min) } \\
\text { eliciting factor: vibratory forces, e.g. pneumatic } \\
\text { vibratory forces }\end{array}$ \\
& $\begin{array}{l}\text { aquagenic urticaria } \\
\text { cholinergic urticaria } \\
\text { contact urticarial } \\
\text { exercise induced anaphylaxis/urticaria }\end{array}$ & $\begin{array}{l}\text { eliciting factor: water } \\
\text { elicitation factor: by increase of body core temperature } \\
\text { due to physical exercises, spicy food } \\
\text { elicitation by contact with urticariogenic substance } \\
\text { eliciting factor: physical exercise }\end{array}$ \\
\hline
\end{tabular}

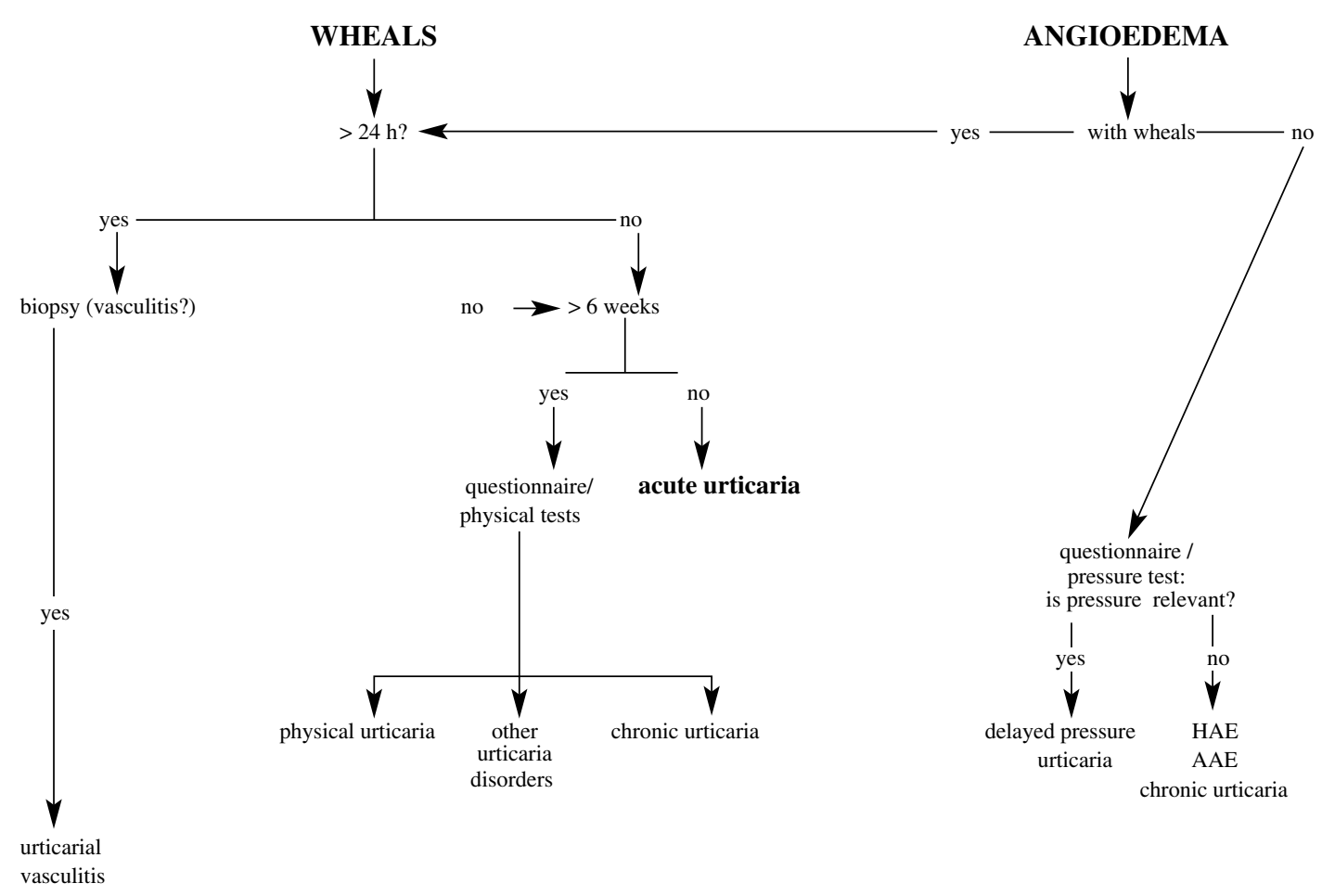

Fig. 1. Differential diagnosis of urticarial symptoms. HAE - hereditary angioedema; AAE - acquired angioedema with C1 esterase inhibitor deficiency [1]

It has been estimated that in about $75 \%$ of cases, causative factors of the chronic type of the disease remain unknown and chronic spontaneous urticaria, also known as chronic idiopathic urticaria (CIU) should be diagnosed. Current data indicate that in $25-60 \%$ of patients with CIU, autoreactive processes are identified (autoreactive spontaneous chronic urticaria) [5-7].

\section{History of the concept of autoimmunity in urticaria}

The concept of autoimmune urticaria (AU) is relatively new while the first reports on the involvement of circulating histamine-releasing factors were published in the 1960s. In 1962, Rorsman stated that the degranulation response of leukocytes is the responsible antigen-antibody 
type of reaction [8]. In 1986, Grattan et al. observed a specific erythematous and wheal-type reaction as a result of an intradermal injection of autologous serum in patients suffering from urticaria [9]. Soon afterwards, Gruber et al. identified a non-functional type of $\operatorname{IgG}$ and $\operatorname{IgE}$ (causing no degranulation of basophils) in patients with chronic urticaria and cold-induced urticaria [10]. In 1991, Grattan et al. reported on IgE autoantibodies, and two years later, the same team discovered that $\mathrm{IgG}$ autoantibodies directed against IgE molecule and a high affinity IgE receptor (FceRI) are major mediators of inflammation and, consequently, the cause of spreading urticarial wheals in chronic urticaria $[11,12]$. This finding was confirmed by other investigators [13, 14]. Additionally, in the 1980s, Leznoff et al. found that more than $14 \%$ of patients with chronic urticaria showed signs and/or symptoms of autoimmunity within the thyroid gland. On the basis of these characteristic autoantibodies, autoimmune urticaria has been further classified into two subgroups:

1) autoimmune urticaria associated with $\operatorname{IgG}$ antibodies, directed against the $\alpha$ chain of the receptor with a high affinity to the Fc portion of immunoglobulin E (FceRI) or against the immunoglobulin $\mathrm{E}$ ( $\operatorname{IgE}$ );

2) autoimmune urticaria associated with the presence of autoantibodies against thyroid antigens:

- anti-thyroglobulin antibodies (anti-TG),

- anti-thyroperoxidase antibodies (anti-TPO),

- anti-thyrotropin receptor (anti-TSH-R).

\section{Mechanism of autoreactivity}

It seems that $\mathrm{IgE}$ antibodies on the surface of mast cells and basophils, bind a specific antigen such as $\operatorname{IgG}$ anti- $\operatorname{IgE}$, which leads to the formation of cross-connections between adjacent FceRI receptors, resulting in the cascade of reactions finally leading to the release of histamine and other mediators of inflammation. The mechanism of degranulation induced by anti-FceRI is similar. The difference is related to the cross-coupled receptors without the involvement of adjacent IgE [15]. In addition to the autoantibodies (mainly IgG1 and IgG3), complement activation and release of anaphylatoxin $\mathrm{C} 5 \mathrm{a}$, which in turn causes mast cell degranulation seems to play an important role. It has been observed that serum $\operatorname{IgG}$ autoantibodies of urticarial patients present the ability to stimulate histamine release from cutaneous mast cells only in the presence of a complement. Thus, degranulation of these cells with FceRI is additionally strengthened by the activation of complement components [16]. The question what the "true" role of autoantibodies in the course of chronic urticaria is still remains not clearly answered. It needs to be clarified whether we are dealing with an epiphenomenon or a classical type of autoreactivity in selected cases of CIU. Kandeel et al. found that sera of patients with Hashimoto thyroiditis may induce degranulation of basophils in the absence of anti-FceRI. Howev- er, they failed to identify the causative factor for this reaction [17]. Rottem drew attention to the possible involvement of anti-IgE class TPO autoantibodies, which may stimulate degranulation of mast cells after exposure to specific circulating antigens. These antigens may be released as a result of thyroid damage related to the autoimmunological process involving the thyroid gland [18]. It seems that such an association of autoimmune thyroiditis with chronic urticaria confirms the basis for evaluation of thyroid autoantibodies in the diagnosis of CIU [19]. Skin reactions in response to IgG-depleted plasma drew attention to the possible role of plasma components in the formation of urticarial wheals. In addition, increased plasma levels of Ddimers, clotting factor VIIa, prothrombin fragment $1+2$, recorded in patients with chronic urticaria may be considered as evidence for extrinsic coagulation cascades activation [20]. The impact of Helicobacter pylori (H. pylori) infection on the production of autoantibodies is another interesting issue. It seems that due to significant cell immunogenicity of bacterial polysaccharides, autoantibodies may arise in relation to specific antigenic mimicry. It has been also reported that $H$. pylori has the ability to induce expression of HLA-DR on gastrointestinal epithelial cells, providing them with characteristics of functionally active antigen presenting cells [21].

\section{Diagnosis of autoimmune urticaria}

Autologous serum skin test (ASST) is regarded to be of a great value in the primary assessment of patients' autoreactivity. Skin reaction of erythematous and/or wheal-type in response to the autologous serum indicates the presence of autoantibodies, which may be responsible for the degranulation of mast cells [22]. First described by Grattan et al. in 1986 [9], ASST contemporarily is applied on a regular basis in the daily clinical practice. A surprisingly wide range of positive results of ASST in patients with chronic urticaria have been reported by different authors (from $4.1 \%$ to $76.5 \%$ ), most probably due to different criteria used for assessment. In terms of methodology, blood sample for analysis is obtained from the clot and then centrifuged for $10 \mathrm{~min}$ (450-500 g). An intradermal injection of $0.05 \mathrm{ml}$ of serum (forearm), $0.05 \mathrm{ml}$ of $0.9 \% \mathrm{NaCl}$ (negative control) and $0.05 \mathrm{ml}$ of histamine (positive control) complete the whole testing procedure. After 30 minutes, results of ASST should be evaluated. There are certain differences in terms of evaluation of final results of testing. According to some authors, a positive result should be recorded when the mean diameter of the wheal is at least $1.5 \mathrm{~mm}$ larger than the negative control. But there are other approaches considering 2, 3 and $5 \mathrm{~mm}$ (mean diameter) to be the minimal values for the positive reading [23-25]. Some authors question the specificity of ASST, pointing to the possibility of obtaining false positive results, in conjunction with the release of significant amounts of bradykinin and $\mathrm{C} 5$ during the coagulation 
process and C5 disruption. According to Asero et al., the autoreactivity detection rate is higher with the autologous plasma test (APST) in comparison to ASST [20, 26]. A positive reaction in APST seems to be related in particular to the function of certain coagulation factors as plasma levels of coagulation factors correlate with the severity of the disease, and this seems to be related to the time point of blood collection [27]. Basically two different anticoagulants are used in the process of plasma preparations for APST, i.e. edetate potassium or sodium citrate. The general methodology of APST does not differ from ASST described above [28]. In conclusion, it seems that further implementation of the APST test allows for a more detailed, while still initial diagnosis of AU. In addition, there are certain restrictions concerning skin autologous tests to be mentioned. From a technical standpoint, there is for example a definite need for the withdrawal of antihistamines for at least three days before the scheduled examination. Concerning logic and interpretation of results one should possibly prove the functional activity of autoantibodies which may simply coexist in the complex and chronic urticarial process. It is believed that the functional significance of these antibodies should be confirmed by performing a histamine release assay (BHRA - basophil histamine release assay), with specificity characterized with Western blot or ELISA [22]. However, due to high costs, availability of these methodologies in our daily practice is rather limited.

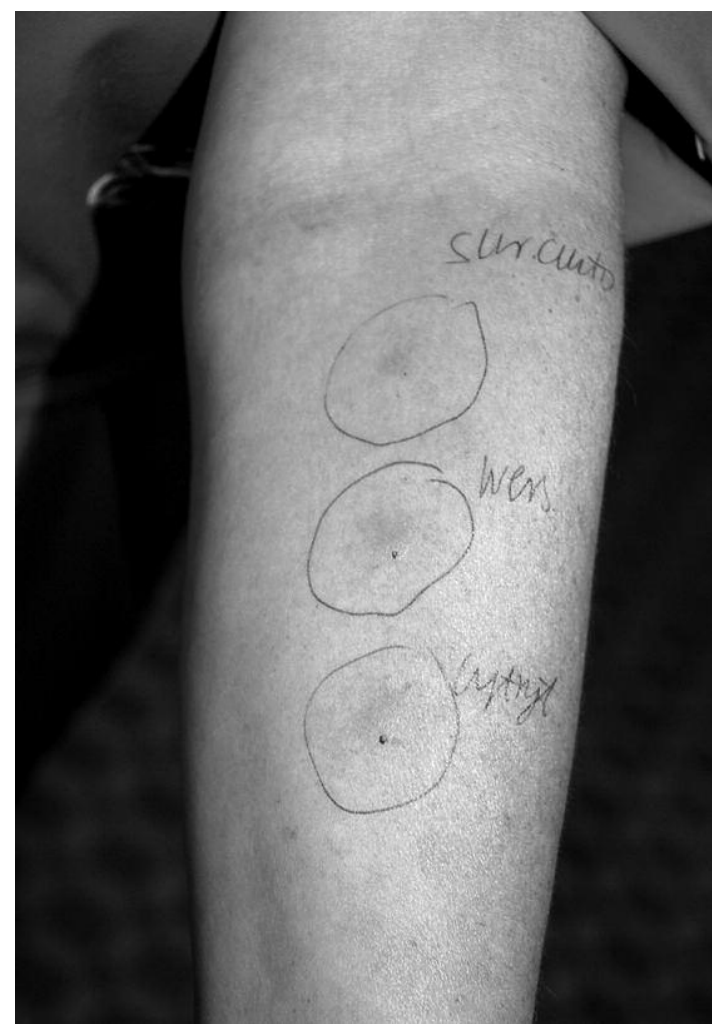

Fig. 2. Positive results of ASST and APST
Patients suffering from AU present with lower serum levels of IgE in comparison to other types of the disease with negative autoantibodies and basopenia seems to be another characteristic phenomenon [8].

Infiltrations within skin lesions in AU are composed predominantly of granulocytes and it seems that histopathological differences between various types of the disease are of no significance [29].

\section{Clinical manifestations of autoimmune urticaria}

Patients with AU usually present higher severity of the urticarial process in terms of the number of urticarial wheals and intensity of itching/burning sensation. They often suffer additionally from other autoimmune diseases (vitiligo, insulin-dependent diabetes, rheumatoid arthritis, autoimmune hepatitis or autoimmune Hashimoto thyroiditis) [30]. Spadoni et al. have reported on cases of urticaria, as the first manifestation of juvenile systemic lupus erythematosus [31]. In terms of treatment, it seems that patients diagnosed with AU need higher doses of antihistamines and/or general modification of therapy, including alternative therapeutic modalities [32, 33].

\section{Treatment of autoimmune urticaria}

In the case of $\mathrm{AU}$, classical treatment even using a new generation of antihistamines is often ineffective. Systemic corticosteroids are not indicated for prolonged treatment due to significant side effects and this group of medications is recommended only in case of emergency.

In patients with hypothyroidism in the course of autoimmune thyroiditis, L-thyroxine may be efficacious. Coexistence of AU, autoimmune thyroiditis, and arthritis with significant improvement in the clinical course of urticaria after treatment with L-thyroxine ( $75 \mathrm{mg}$ daily) has been described by Milchert et al. [34]. Also Rumbyrt et al. published good treatment results in seven patients with chronic urticaria and autoimmune euthyroid thyroiditis, treated with daily doses of 25-100 mg of L-thyroxine. In the control group composed of patients with chronic urticaria, but with no thyroid autoimmunity, treatment with L-thyroxine was not successful [35]. Obviously, further investigations and DBPC clinical trials are necessary to prove this important therapeutical concept.

Cyclosporine $\mathrm{A}(\mathrm{Cs} \mathrm{A})$ is a good alternative for the treatment of severe cases of AU. Boubouka et al. have proven that even low doses of CsA may be effective. He started treatment with an initial dose of $1.5-2.5 \mathrm{mg} / \mathrm{kg}$, then being reduced on a monthly basis in relation to the individual clinical course, for the global treatment period of 5 months in 30 patients. The daily dose of $0.55 \mathrm{mg} / \mathrm{kg}$ was the lowest to control the urticarial process. Twenty-three patients completed the study. After the first month of treatment, an 
improvement of $31 \%$ was noted, reaching $88 \%$ after the fifth month of treatment. Six months after the final study end-point, ASST has been repeated and negative results were recorded in $78.3 \%$ of patients who completed the study. At one-year follow-up, 20 patients were symptomfree and 3 had relapsed [36]. Efficacy of CsA in comparison with prednisolone has been studied by Lori et al. [37], and good evidence for alternative treatment in the case of contraindications for systemic steroids in severe AU has been provided.

Mofetil mycophenolate may be also considered for the treatment of AU patients. Doses ranging from 1000 to 6000 $\mathrm{mg} /$ day and mean treatment duration of 14 weeks have been investigated. A significant clinical improvement was observed in up to $91 \%$ of AU patients with dyspepsia being the most common side effect [38]. Biologicals are obviously of a great interest for the treatment of AU. Omalizumab for instance may reduce serum $\mathrm{IgE}$ levels as well as expression of Fc?RI on mast cells and basophils [39]. Therefore, it may be truly needed for those presenting for instance autologous as IgE directed against thyroid antigens. However, due to a wide panel of diverse biological contradictions to therapy, detailed and cautious recruitment for the biological treatment is absolutely necessary. A high price of biologicals is another crucial limitation on treatment of AU patients with this particular group of medications.

There are also other alternative therapeutical modalities available such as hydroxychloroquine [40] and plasmapheresis [41], intravenous immunoglobulins, methotrexate, tacrolimus, interferon, dapsone, and sulfasalazine. Of course, further investigations and stronger evidence for their clinical efficacy are necessary [42, 43]. Anticoagulants are also an interesting therapeutical approach but further trials are still needed $[44,45]$.

In conclusion, chronic spontaneous urticaria is one of the most frequent skin disorders, and often people have been suffering from it for many years. It strongly affects the daily quality of life of patients and therefore the frequency of psychiatric comorbidities is high. Autoimmune urticaria seems to be one of the most difficult to treat variants of CIU as the underlying cause of the disease still remains unclear. Diagnostic procedures such as ASST, APST and evaluation of autoantibodies are recommended for the first-line diagnosis. However, there is a strong need for new methodologies of higher specificity, sensitivity and describing functional characteristics of the autoreactive process in AU. High doses of non-sedating antihistamines are usually ineffective and alternative therapeutical approaches including immunosuppression are often recommended in order to improve care for a large proportion of $\mathrm{AU}$ patients.

The authors declare no conflict of interest.

\section{References}

1. Zuberbier T, Asero R, Bindslev-Jensen C, et al. (2009): EAACI/GA2LEN/EDF/WAO guideline: definition, classification and diagnosis of urticaria. Allergy 64: 1417-1426.

2. Szulczyńska-Gabor J, Czarnecka-Operacz M (2003): Autoimmune chronic urticaria - diagnostic and therapeutic possibilities. Pol Merk Lek 14: 82-85.

3. Obtułowicz K, Obtułowicz A (2002): Urticaria and angioedema. Alergia Astma Immunol 7 Suppl 2: 101-107.

4. Axelrod S, Davis-Lorton M (2011): Urticaria and angioedema. Mt Sinai J Med 2011; 78: 784-802.

5. Goh CL, Tan KT (2009): Chronic autoimmune urticaria: where we stand? Indian J Dermatol 2009; 54: 269-274.

6. Greaves M (2002): Autoimmune urticaria. Clin Rev Allergy Immunol 2002; 23: 171-183.

7. Magen E, Mishal J (2012): The effect of L-thyroxine treatment on chronic idiopathic urticaria and autoimmune thyroiditis. Int J Dermatol 51: 94-97.

8. Rorsman H (1962): Basophilic leucopenia in different forms of urticaria. Acta Allergol 17: 168-184.

9. Grattan CE, Wallington TB, Warin RP, et al. (1986): A serological mediator in chronic idiopathic urticaria - a clinical, immunological and histological evaluation. Br J Dermatol 114: 583-590.

10. Gruber BL, Baeza ML, Marchese MJ, et al. (1988): Prevalence and functional role of anti - IgE autoantibodies in urticarial syndromes. J Invest Dermatol 1988; 90: 213-217.

11. Grattan CE, Francis DM, Hide M, Greaves MW (1991): Detection of circulating histamine releasing autoantibodies with functional properities of anti IgE in chronic urticaria. Clin Exp Allergy 21: 695-704.

12. Hide M, Francis DM, Grattan CE, et al. (1993): Autoantibodies against the high - affinity IgE receptor as a cause of histamine release in chronic urticaria. N Engl J Med 328: 1599 1604.

13. Fiebiger E, Maurer D, Holub H, et al. (1995): Serum IgG autoantibodies directed against the alpha chain of FceRI: a selective marker and pathogenetic factor for a distinct subset of chronic urticaria patients? J Clin Invest 96: 2606-2612.

14. Ferrer M, Kinét JP, Kaplan AP (1998): Comparative studies of functional and binding assays for IgG anti-FceRI $\alpha$ ( $\beta$-subunit). J Allergy Clin Immunol 101: 672-676.

15. Sabroe RA, Greaves MW (1997): The pathogenesis of chronic idiopathic urticaria. Arch Dermatol 133: 1003-1008.

16. Sabroe RA, Francis DM, Barr RM, et al. (1998): Anti-Fc?RI autoantibodies and basophil histamine releasability in chronic idiopathic urticaria. J Allergy Clin Immunol 102: 651-658.

17. Kandeel AA, Zeid M, Helm T, et al. (2001): Evaluation of chronic urticaria in patients with Hashimoto thyroiditis. J Clin Immunol 21: 335-347.

18. Rottem M (2003): Chronic urticaria and autoimmune thyroid disease: is there a link? Autoim Rev 2: 69-72.

19. Palma-Carlos AG, Palma-Carlos ML (2005): Chronic urticaria and thyroid autoimmunity. Eur Ann Allergy Clin Immunol 37: 143-146.

20. Asero R, Tedeschi A, Riboldi P, Cugno M (2006): Plasma of patients with chronic urticaria shows signs of thrombin generation, and its intradermal injection causes wheal - and flare reactions much more frequently than autologous serum. J Allergy Clin Immunol 2006; 117: 1113-1117.

21. Greaves MW (2001): Chronic idiopathic urticaria (CIU) and Helicobacter pylori. Allergy Clin Immunol Int 2001; 13: 23-26. 
22. Konstantinou GN, Asero R, Maurer M, et al. (2009): EAACI/GA2LEN task force consensus report: the autologous serum skin test in urticaria. Allergy 1256-1268.

23. Garmendia JV, Zabaleta M, Aldrey O, et al. (2006): Immunophenotype characteristics of peripheral blood mononuclear leukocytes of chronic idiopathic urticarial patients. Invest Clin 2006; 47: 361-369.

24. Bagenstose SE, Levin L, Bernstein JA (2004): The addition of zafirlukast to cetirizine improves the treatment of chronic urticarial in patients with positive autologous serum skin test results. J Allergy Clin Immunol 113: 134-140.

25. Erbagci Z (2004): Multiple NSAID intolerance in chronic idiopathic urticarial is correlated with delayed, pronounced and prolonged autoreactivity. J Dermatol 31: 376-382.

26. Metz M, Giménez-Arnau A, Borzova E, et al. (2009): Frequency and clinical implications of skin autoreactivity to serum versus plasma In patients with chronic urticaria. J Allergy Clin Immunol 2009; 123: 705-706.

27. Asero R, Riboldi P, Tedeschi A, et al. (2007): Chronic urticaria: a disease at a crossroad between autoimmunity and coagulation. Autoimmun Rev 7: 71-76.

28. Godse KV (2008): Autologous serum skin test v/s autologous plasma skin test. Indian J Dermatol Venereol Leprol 2008; 74: 496-497.

29. Grattan CE, Boon AP, Eady RA, Winkelmann RK (1990): The pathology of the autologous serum skin test response in chronic urticaria resembles IgE-mediated late phase reactions. Int Arch Allergy Immunol 93: 198-204.

30. Ju HY, Kim HS, Kim HO, Park YM (2009): Cyclosporine treatment In a patients with concurrent autoimmune urticaria and autoimmune hepatitis. Ann Dermatol 21: 291-293.

31. Spadoni M, Jacob C, Aikawa N, et al. (2011): Chronic autoimmune urticaria as the first manifestation of juvenile systemic lupus erythematosus. Lupus 20: 763-766.

32. Sabroe RA, Seed PT, Francis DM, et al. (1999): Chronic idiopathic urticaria: comparision of the clinical features of patients with and without anti - FceRI or anti - IgE antibodies. J Am Acad Dermatol 40: 443-450.

33. Staubach P, Eckhardt-Henn A, Dechene M, et al. (2006): Quality of life in patients with chronic urticaria is differentially impaired and determined by psychiatric comorbidity. Br J Dermatol 154: 294-298.

34. Milchert M, Fliciński J, Ostanek L, Brzosko M (2007): Chronic urticaria and mild arthritis associated with autoimmune thyroid disease: successful treatment with L-thyroxine. Acta Derm Venereol 87: 263-264.

35. Rumbyrt JS, Katz JL, Schocket AL (1995): Resolution of chronic urticaria in patients with thyroid autoimmunity. J Allergy Clin Immunol 96: 901-905.

36. Boubouka CD, Charissi C, Kouimintzis D, et al. (2011): Treatment of autoimmune urticaria with low-dose cyclosporin A: a one-year follow-up. Acta Derm Venereol 91: 50-54.

37. Loria MP, Dambra PP, D’Oronzio L, et al. (2001): Cyclosporin A in patients affected by chronic idiopathic urticaria: a therapeutic alternative. Immunopharmacol Immunotoxicol 23: 205-213.

38. Zimmerman AB, Berger EM, Elmariah SB, Soter NA (2012): The use of mycophenolate mofetil for the treatment of autoimmune and chronic idiopathic urticaria: experience in $19 \mathrm{pa}-$ tients. J Am Acad Dermatol 66: 767-770.

39. Kaplan AP, Joseph K, Maykut RJ, et al. (2008): Treatment of chronic autoimmune urticaria with omalizumab. J Allergy Clin Immunol 122: 569-573.
40. Reeves GE, Boyle MJ, Bonfield J, et al. (2004): Impact of hydroxychloquine therapy on chronic urticaria: chronic autoimmune urticaria study and evaluation. Intern Med J 34: 182-186.

41. Greaves M (2000): Chronic urticaria. J Allergy Clin Immunol 105: 664-672.

42. Zuberbier T, Asero R, Bindslev-Jensen C, et al. EAACI/ GA2LEN/EDF/WAO guideline: management of urticaria. Allergy 2009; 64: 1427-1443.

43. Gomułka K (2012): Cold urticaria: a case report. Post Dermatol Alergol 29: 60-62.

44. Fagiolo U, Cancian M, Bertollo L, et al. (1999): Inhibitory effect of heparin on skin reactivity to autologous serum in chronic idiopathic urticaria. J Allergy Clin Immunol 103: 1143-1147.

45. Grzelewska-Rzymowska I, Górski P (2011): Rupatadine: a novel second-generation antihistamine. Post Dermatol Alergol 28: 480-488. 